\title{
O COVID-ı9 E MEIO AMBIENTE, EDUCAÇÃO AMBIENTAL COMO FERRAMENTA ALTERNATIVA PARA CONSCIENCIALIZAÇÃO DAS PESSOAS
}

\author{
Manuel Pastor Francisco Conjo ${ }^{1}$ \\ Octávio Manuel de Jesus ${ }^{2}$ \\ Rosalina Inácio Fumo ${ }^{3}$ \\ Carolina da Glória Dinis Conjo ${ }^{4}$ \\ Vitor Alves da Silveira ${ }^{5}$
}

RESUMO: A pandemia da nova corona vírus, COVID-19, impôs-se no mundo trazendo consigo uma série de mudanças na vida das pessoas por todo o planeta assim como, o agravamento de alguns problemas ambientais. Mas também, as diversas medidas adotadas com vista ao controle da pandemia, foram de grande contributo para algumas melhorias que se observam no meio ambiente. Notável, por exemplo pela redução nos níveis de emissões atmosféricas, redução nos níveis de poluição por resíduos sólidos nos locais de maior aglomeração de pessoas. A educação ambiental é, portanto, vista como um componente importante para a conscientização das pessoas de modo a se travar o acelerado grau de infecção pelo vírus. O objetivo desta abordagem foi alcançado através de uma metodologia

\footnotetext{
I Doutorando em Ciência Florestal pela Universidade Federal de Viçosa-Minas Gerais-Brasil. Instituição: Universidade Pedagógica de Maputo/Universidade Federal de Viçosa. Mestrado em Gestão Ambiental pela Universidade Pedagógica de Maputo-Moçambique. Bacharel e Licenciado em Ensino de Geografia pela Universidade Pedagógica de Maputo-Moçambique. Técnico Superior em Higiene e Segurança no Trabalho e Meio Ambiente pela Ensine Moçambique.E-mail: pastorconjooo7@gmail.com.

${ }^{2}$ Doutor em Ciências Pedagógicas, Moçambicano,funcionário do Ministério da Ciência, Tecnologia e Ensino Superior.Doutoramento (2003),em Ciências Pedagógicas, componente Educação Ambiental, através da disciplina de Geografia, no Instituto Central das Ciências Pedagógicas de Havana-Cuba. Mestrado (1998),em Didáctica da Geografia, Menção Geografia Económica e Social, no Instituto Superior Pedagógico "Enrique José Varona” em Havana- Cuba. Licenciatura (1992)em Ensino de História e Geografia, no Instituto Superior Pedagógico de Maputo-Moçambique.Docente na Universidade Pedagógica de Maputo (desde 2006), categoria Professor Auxiliar, nas seguintes cadeiras científicas: Gestão Ambiental e Educação Ambiental; Didáctica de Geografia; Geografia de Moçambique I e II; Temas de Actualidade em Geografia Física Geral e Geografia Física Regional.Membro de Júri, Supervisor e Arguente nas Defesas de Monografias, Dissertações em HavanaCuba e Maputo-Moçambique.Supervisor das teses de Doutoramento em Moçambique. Correio electrónico: Octaviom20or@yahoo.es.

${ }_{3}^{3}$ Bacharel e Licenciado em Ensino de Geografia pela Universidade Pedagógica de Maputo-Moçambique. Mestre em Gestão Ambiental pela Universidade Pedagógica de Maputo-Moçambique. Doutoranda em Geografia pela Universidade Pedagógica de Maputo. Instituição: Universidade Pedagógica de Maputo-Moçambique. Email:rosalinafumo@yahoo.com.br

4 Licenciatura em Biologia e Saúde pela Universidade Eduardo Mondlane-Moçambique. Instituição: Departamento de Ciências Biológicas-Universidade Eduardo Mondlane. E-mail:conjocarolina@gmail.com.

5 Doutorando em Ciências Ambientais e Florestais.Universidade Federal Rural do Rio de Janeiro/PPGCAF. Mestre em Ciência Florestal pela Universidade Federal de Viçosa/PPGCF.Engenheiro Agrônomo pela Universidade Federal de Viçosa. Gestor Ambiental-Instituto Superior de Tecnologia de Paracam. Email:vitoralvesilveira@gmail.com.
} 
qualitativa na qual, por via da consulta bibliográfica, foi possível fazer uma descrição do atual cenário que assola a humanidade. Tendo se concluído que as características do meio ambiente envolvente provocam aceleração ou não do grau de infecção pelo vírus assim como, o COVID-ı9 estimulou substancialmente nos níveis de geração de resíduos sólidos mas por outro lado, as medidas de confinamentos e restrições adotadas em todos os países, conferiram um conjunto de alterações que proporcionaram melhorias substantivas a qualidade ambiental, onde a Educação Ambiental é eleita para mudança no comportamento das pessoas para salvaguardar o bem estar público global.

Palavras Chaves: COVID-19. meio ambiente. educação ambiental.

ABSTRACT: The pandemic of the new corona virus, COVID-i9, has imposed itself in the world, bringing with it a series of changes in people's lives all over the planet, as well as the aggravation of some environmental problems. But also, the various measures adopted with a view to controlling the pandemic, were a great contribution to some of the improvements observed in the environment, notable, for example, by the reduction in the levels of atmospheric emissions, reduction in the levels of pollution by solid waste in the places of greater agglomeration of people. Environmental education is, therefore, seen as an important component for raising people's awareness in order to stop the accelerated degree of infection by the virus. The objective of this approach was achieved through a qualitative methodology in which, through bibliographical consultation, it was possible to make a description of the current scenario that devastates humanity. Having concluded that the characteristics of the surrounding environment cause acceleration or not of the degree of infection by the virus as well, COVID-i9 substantially stimulated the levels of solid waste generation but, on the other hand, the containment measures and restrictions adopted in all The countries conferred a set of changes that provided substantial improvements to environmental quality, where Environmental Education is elected to change people's behavior to safeguard the global public well-being.

Keywords: COVID-19. Environment. environmental education.

\section{INTRODUÇÃO}

A pandemia de COVID-ı́ é um cenário atual que assola todo o mundo com a preocupação do alto potencial de contágio do vírus SARS-CoV-2, em consonância com observação dos números de casos e óbitos, mesmo com a baixa letalidade proporcional ao total de casos (DO CARMO et al., 2020).

Em dezembro de 2019, a China identificou um surto de uma síndrome respiratória aguda em trabalhadores de um mercado de alimentos e animais vivos em Wuhan, causado por um novo coronavírus (SARS-CoV-2). Esse vírus é pertencente à família Coronaviridae e 
provoca a doença respiratória denominada COVID-I9. Os impactos dessa doença começaram a ser percebidos no setor saúde e na economia mundial no início de 2020 (MARINELLI et al., 2020).

O SARS-CoV-2 tem alta transmissibilidade, que se dá pelo contato de pessoa a pessoa e por meio de fômites, podendo permanecer viável em superfícies do ambiente por mais de 24 horas. A síndrome respiratória aguda provocada por ele pode variar de casos leves (cerca de 80\%) a casos muito graves com insuficiência respiratória (5\% a 10\%) (SILVA, 2020). A letalidade também é variável, dependendo da faixa etária e de condições clínicas associadas. $\mathrm{O}$ SARS-CoV-2 se disseminou rapidamente, atingindo mais de roo países nos cinco continentes, o que levou a Organização Mundial da Saúde (OMS) a declarar a COVID-ı9 como uma pandemia no dia ir de março de 2020 (MARINELLI et al., 2020). Nos dias atuais, embora com crescente tendência de controlo pela vacina, em alguns países no mundo, a epidemia prossegue em ritmo veloz (SILVA, 2020).

Várias infecções humanas desconhecidas até os últimos anos são em sua maioria de origem viral. As doenças ditas reemergentes, principalmente as virais como o COVID-I9, acontecem por meio de três mecanismos possíveis. Estes estão relacionados às modificações dos vírus, incluindo o surgimento de novas variantes; à capacidade de transpor a barreira de espécie; ou à disseminação de determinado vírus, a partir de uma pequena população humana ou animal, na qual ele surgiu ou foi originalmente introduzido (SCHMIDT, 2007). Dentre os mecanismos relacionados com o surgimento das doenças, a degradação ambiental é citada como condição frequente, porém é pouco considerada em estratégias de políticas públicas.

Tendo em conta o acelerado número de pessoas contraindo o novo coronavírus na maioria dos países do mundo, torna-se imprescindível um trabalho exaustivo no monitoramento do vírus COVID-r9 para conter a epidemia. Considera-se também indispensável a necessidade de adoção de medidas de caráter ambiental, econômico e social, assim como a aplicação de uma medida que vise consciencializar mais as pessoas dos riscos e formas corretas de ações individuais e coletivas com o propósito de estancar a propagação do vírus, nas comunidades, nas urbes e no planeta em geral. 
Importa referir que o ambiente, é meio pelo qual se transmite o Vírus do COVID-I9 sobre tudo pelo ar. Olha -se para nossa temática nessa perspectiva, mas também considera-se os impactos do confinamento e limitação da circulação humana nos diferentes lugares, como tendo sido determinante para a contenção e redução no número de infecções pelo vírus, assim como tendo sido de capital importância sob ponto de vista de gestão do meio ambiente, ora pela redução de emissões atmosféricas, deposição irregular de resíduos, pressão sobre os recursos, entre outros.

O comportamento dos causadores dos principais problemas ambientais no planeta, é um aspecto essencial para o sucesso da implementação de um sistema eficiente salvaguarda da saúde pública, controle de algumas doenças infecciosas e conservação ambiental. Por esta razão, a educação ambiental e cívica é um aspecto importante, o qual deve ser realizado de maneira integrada e coordenada.

Existem vários meios para realizar a educação ambiental e cívica, entre eles destacamse as reuniões á nível dos bairros, distribuição de folhetos, campanhas de limpeza, uso dos meios de comunicação social e cartazes nos locais de aglomeração e de deposição de resíduos. É importante que as ações sejam coordenadas pelos diferentes países no mundo, envolvendo diferentes atores tais como escolas, associações, autoridades locais, igrejas, ONG's e comunidade em geral (MICOA, 2010).

O presente estudo é qualitativo e o método de abordagem usada é descritiva, feita com recurso ao método de pesquisa bibliográfica. O que permitiu a utilização de informações primárias e secundárias sobre a pandemia do COVID-I9. Refira-se que as informações utilizadas para fundamentar o presente estudo tiveram, como base, temáticas relacionadas a pandemia do novo coronavírus.

Este artigo tem por objetivo trazer uma abordagem conectiva do COVID-I9 versus meio ambiente e educação ambiental como ferramenta de ação de conscientização das pessoas de forma a reduzir os níveis de infecção e consequentemente travar o alastramento da pandemia. 


\section{Metodologia}

Trata-se de um estudo descritivo, baseado em vários estudos realizados desde que se instaurou no mundo o novo "paradigma pandêmico", o COVID-ıg.

Por outro lado, o presente estudo é uma abordagem qualitativa da literatura, campo da pesquisa social, que se apoia em dados sobre o mundo, que são construídos nos diferentes processos (CONJO et al, 202I), de modo a permitir a análise precisa do tema em estudo, baseado no método de pesquisa bibliográfica, que segundo SEVERINO (2007), pode-se entender como um instrumento metodológico de suma importância na discussão analítica dos temas investigados.

\section{Resultados e Discussões}

Numa perspectiva qualitativa, após apreciação de vários estudos e outras informações relevantes acerca do COVID-ı9 desde a sua eclosão aos dias atual, facilmente pode-se chegar a resultados inequívocos da conectividade das pandemias ao meio ambiente assim como da necessidade de um mecanismo mais envolvente, visando maior conscientização das pessoas quanto as medidas de prevenção contra o vírus e conservação ambiental. Da mesma forma, discussões foram levantadas de modo a argumentar os resultados do estudo, podendo destacar:

RI: O meio ambiente e suas caraterística determinam o grau de infecção pelo vírus COVID-I9, pelas várias relações e aspectos que são condicionados pelo meio envolvente de determinados grupos de sociais e suas ações.

Dr: De acordo com YOUNG e MATHIAS (2020), existem diversos fatores que influenciam a emergência de novas doenças infecciosas ou no ressurgimento de outras, já antes conhecidas. Algumas epidemias resultam diretamente de processos evolutivos naturais dos patógenos ao longo do tempo. Há, porém, aquelas que surgem como consequência da ação humana, mais especificamente como consequência da degradação do meio ambiente. Num estudo de 2015, apresentado no Fórum Econômico Mundial, em Davos, pesquisadores da EcoHealth Alliance estimaram que nos 17 anos anteriores, 31\% dos surtos epidêmicos (e.g., 
nipah, ebola e zika) estavam ligados ao desmatamento ( $\mathrm{LOH}, 2015)$, isto é, ligados à perda de habitats naturais e a redução da diversidade biológica. Na Amazônia, o desmatamento cria condições para a proliferação do Anopheles darlingi - o mais importante transmissor de malária na região. As larvas desse mosquito se proliferam em poças d'água parcialmente abrigadas do sol, como as que se formam nas estradas abertas dentro da floresta e no limite entre a mata e a área recém-desmatada. Acredita-se ter se gerado em Wuhan uma atmosfera ambiental propensa para eclosão da pandemia, condicionada pelo meio ambiente.

A importância do meio ambiente para a saúde é um conhecimento que remonta à Antiguidade. Uma das referências mais importantes é o célebre Tratado "Dos Ares, Águas e Lugares” de Hipócrates. Sabemos como diversas civilizações antigas aplicavam princípios fundamentais de higiene, tentando rodear-se dos ambientes mais saudáveis possíveis. Um dos casos mais exemplares terá sido o das obras de saneamento básico dos romanos, abrangendo a distribuição de água potável e a deposição cuidada dos resíduos (MIGUEL; REIS, 2015).

Ainda segundo MIGUEL e REIS (2015), a relação entre o ambiente e as doenças transmissíveis há muito que é evidenciada, sobretudo pela presença de vetores e agentes microbiológicos. Modernamente, esta evidência surge reforçada pela presença de vectores $e$ agentes em regiões onde eram raros ou desconhecidos e da subsequente ocorrência das doenças que transmitem.

As alterações do clima e as situações extremas a que dão origem (chuvas torrenciais e subsequentes inundações, secas prolongadas, ou ventos fortes, fenómenos normalmente acompanhados pela falência nos sistemas de abastecimento de água potável, alimentos e saneamento) são também relevantes fatores ambientais que influenciam a propagação de doenças transmissíveis, como as diarreicas, susceptíveis de causar epidemias (LIM et al., 2012). O aspeto ambiental é bastante relevante, já que se sabe que o COVID-i9 adapta-se melhor em baixas temperaturas, deste modo o clima torna-se razão bastante preponderante para o comportamento do vírus e sua propagação.

O COVID-ı9, tendo rápida propagação, logo vieram as restrições, com a suspensão das operações industriais em toda a região e a proibição de viagens, reduzindo o fluxo de 
circulação de carros, ônibus, trens e aviões em todos os países, o que alterou visivelmente as caraterísticas ambientais dos lugares que por sua vez, tais caraterísticas condicionaram no nível de infecção (DE SOUZA, 2020).

DE TROI e QUINTILIO (2020), apontam que a COVID-19 atingiu diretamente o sistema de globalização e mobilização de serviços e pessoas. Alterações no modo de vida e funcionamento da sociedade foram adotadas como tentativas de conter a disseminação do vírus, como o distanciamento, isolamento social e a quarentena. O bloqueio desse sistema teve suas consequências diretas e indiretas nos diversos setores sociais, como o econômico e o ambiental (DE SOUZA, 2020). Mais, uma vez aponta-se o ambiente como fator determinante, visível pelas radicais alterações que se evidenciaram após restrições quanto ao seu acesso. Acredita-se por tanto, na forte capacidade que o ambiente e suas caraterísticas impõem no controlo ou alastramento da pandemia.

R2: O COVID-I9 contribui para o agravamento de alguns problemas ambientais já conhecidos, pelos impactos produzidos das medidas adoptadas para a contenção da pandemia, principalmente a de confinamento domiciliar integral.

D2: A pandemia do novo coronavírus não afetou apenas a saúde de milhões de pessoas. Ela também provocou profundas implicações à economia, às formas de relacionamentos e às questões ambientais por alguns excessos que tornaram nocivos ao meio ambiente global (DA CONCEIÇÃO SILVA et al., 2020).

Por outro lado, salienta-se a existência também de impactos ambientais negativos provocados pelo COVID-ı9. Onde o maior deve ser na produção de alimentos, observando-se que pessoas estão em casa na maior parte do seu tempo, consequentemente consumindo mais comida, água, energia, serviços como comunicação, e gerando muitos resíduos. Sendo que, a geração de lixo, figura-se o segundo impacto mais considerável que afeta o meio ambiente (UFJF, 2020).

O problema com os resíduos sólidos ganha dimensões ainda mais alarmantes quando considerado que atualmente, milhares de toneladas de lixo contaminado com o vírus de VOVID-19 em casa por todos os países, onde paciente da doença estão insolados, em 
tratamento. Sendo que, sobre a dimensão desse lixo, não se tem estimativas aproximadas de quantidades, uma vez que não se sabe ao certo, afinal, quantas pessoas contaminadas estão em suas casas, muito menos os impactos gerados por esse lixo sobre o meio ambiente (BORGES, 2020).

De acordo com DE SOUZA (2020), quanto aos resíduos, houve aumento da produção de resíduo sólido hospitalar. por sua vez HE (2020), faz menção dando conta que em Wuhan, local onde se diagnosticou o paciente "Zero" que testou COVID-I9 positivo, portanto, o primeiro epicentro da crise da doença na China, a quantidade de lixo cresceu quatro vezes, por exemplo.

Terminando DA COSTA (2020), afirma que o saneamento básico, como a limpeza de áreas públicas, coleta e controle da produção dos resíduos sólidos (inclusive os resíduos domésticos e de saúde que aumentaram durante a pandemia), abastecimento de água, drenagem adequada e esgotamento sanitário são de extrema importância para evitar pandemias futuras e para controlar a incidência de doenças, assim como do novo Corona vírus.

R3: As diversas medidas adotadas por todos os países com vista ao controlo do COVID-ı9 contribuíram para a conservação ambiental, e consequente redução de casos de infecção.

D3: A manifestação social sobre os reflexos da pandemia da COVID-ı́ no meio ambiente foi observada com intensidade na internet. Por exemplo, o compartilhamento de imagens e vídeos de paisagens, antes escondidas por camadas de lodos, resíduos ou gases de poluição atmosférica, agora límpidas e visualmente recuperadas foram muitos mencionadas no início do período de isolamento social em diversos lugares do mundo (DE SOUZA, 2020).

Segundo o estudo realizado pela UFJF (2020), dá conta de Imagens de satélite mostrando que a pandemia do coronavírus está atualmente diminuindo níveis de poluição do ar ao redor do mundo. A quarentena é apontada por especialistas como o evento de maior escala já registrado em termos de redução de emissões industriais. Por sua vez, a Agência Espacial Europeia (ESA) detectou ainda uma redução de dióxido de nitrogênio ( $\mathrm{NO}_{2}$ ), 
composto químico que contribui para a poluição atmosférica e para a chuva ácida. $\mathrm{O}_{2} \mathrm{NO}_{2}$ é resultado de emissões de carros e outros processos industriais, podem, entre outras coisas, causar problemas respiratórios.

Já em Nova York, pesquisadores apontaram uma queda dos níveis de carbono em mais de 50\% abaixo da média. Na China, o fechamento de lojas e indústrias resultou uma queda de $25 \%$ nas emissões de dióxido de carbono $\left(\mathrm{CO}_{2}\right)$, o que equivale a uma redução global de 6\%. $\mathrm{Na}$ Itália, país que sofre com o isolamento social há mais tempo, golfinhos foram filmados nadando no porto de Cagliari, capital da ilha de Sardenha. Os canais de Veneza também estão consideravelmente mais limpos e cristalinos após uma semana de quarentena, estado que não atingia há 60 anos. Pesquisadores explicam que o lodo do rio, que geralmente ficava na superfície graças à movimentação de barcos, afundou e foi transportado pelo fluxo da água, que também está mais intenso (UFJF, 2020). Em contrapartida, o ar está mais limpo e até a água dos rios pode melhorar; um freio necessário para uma sociedade imediatista e egocêntrica" (UFJF, 2020).

R4: A educação ambiental cívica é uma importante ferramenta da gestão ambiental, a

qual, quando realizada de maneira integrada e coordenada assume um importante papel para conscientizar e travar os níveis de infecção pelo COVID-ıg.

D4: No século XIX e início do XX, as epidemias serviram para implantação de projetos higienistas que extrapolavam as questões ligadas à limpeza das cidades (DE TROI; QUINTILIO, 2020). Tais projetos requeriam um conjunto de medidas educacionais para a sua efetivação.

Nesse contexto de mudanças causadas pelas restrições necessárias na pandemia do COVID-19, impedimento no ritmo da sociedade induziu questionamentos sobre a maneira que as relações sociais, econômicas e ambientais estavam sendo realizadas. A contenção da pandemia na rotina da globalização, dessa forma, tornou-se pauta das deliberações sobre ser ou não o momento de reestruturar a sociedade como se conhece (DE SOUZA, 2020).

Desta forma, após aprofundar as informações, deve-se e precisa-se mudar os hábitos, para que se possa consumir de forma mais sustentável; ainda, ressalta-se a educação 
ambiental para as crianças e não só, atuarem futuramente como instrumentos de transformação para garantir a condição de vida ideal e equilibrada social, econômica e ambientalmente, sendo a possibilidade de resultados a médio e longo prazo a partir do impacto causado até hoje (MUNDIA, 2019). A sustentabilidade é a ação-base de transformação da sociedade, que sairá de um modo de consumo desenfreado, deixando de buscar as facilidades e o consumo excessivo. Portanto, fica o questionamento, se vai-se esperar uma mutação mais letal para verificar a necessidade de mudanças do cotidiano em prol da melhor qualidade do meio ambiente e, consequentemente, da vida na terra (GRAULT et al., 2018).

Segundo a Organização mundial da Saúde, é necessário educar plenamente e as pessoas em geral sobre a seriedade do COVID-ig e do seu papel de cada um na prevenção do vírus e controlo da sua propagação. Uma vez que essa pandemia atua de forma difícil de controlar, não como desejar-se-ia que fosse, um vírus com enormes transtornos a saúde pública, embora com uma letalidade não muito elevada.

Só será possível traçar uma estratégia para frear a degradação ambiental se os

governos, de maneira geral, não afrouxarem suas políticas de meio ambiente, reforçando a componente educacional (educação ambienta) (UFJF, 2020).

Com o atual "paradigma pandêmico" instaurado pelo mundo todo, sensibilizar a sociedade quanto à exploração desordenada do ambiente natural tornou-se uma necessidade proeminente. Neste contexto, a Educação Ambiental (EA) apresenta-se com uma estratégia responsável para (re)orientar práticas interdisciplinares, com a finalidade de fazer emergir a corresponsabilidade de cada indivíduo quanto ao uso e apropriação dos recursos disponíveis na natureza (JACOBI, 2003). Acreditando que a adoção de novos comportamentos poderá ser de capital importância para o controlo da nova corona vírus assim como de outras futuras eventuais pandemias.

Ao se compreendera educação, como prática social, pretende-se munir as sociedades na conquista de um desenvolvimento fundamentado na construção da sustentabilidade. Deste modo, a educação é o mecanismo que tem dado primazia para adoção de novas práticas 
teóricas e metodológicas capazes de transformar o modus operandi da sociedade em suas distintas dimensões (social, ambiental, econômica), visando à formação irrestrita do homem em estrita consonância com a natureza (DA CONCEIÇÃO SILVA et al., 2020).

As abordagens sobre as práticas sociais que por vezes conduzem a contração de novas doenças e ou mesmo o agravamento das já existentes, são um cenário marcado pela degradação ambiental, envolve indispensável integração de sentidos sobre Educação Ambiental (EA). Desta forma, a dimensão ambiental tem se apresentado como uma proposta que busca envolver atores da área educacional, a fim de potencializar o comprometimento e o compartilhamento de conhecimento por meio de práticas interdisciplinares (JACOBI, 2003), com vista ao controlo de certas patologias

Desse modo, a EA apresenta-se como aliada junto ao desenvolvimento de práticas que sejam capazes de minimizar os impactos desencadeados pela deturpada relação sociedade/natureza. Em tempos de isolamento social -marcado pela pandemia do novo coronavírus -a sociedade tem experimentado uma reclusão necessária, porém, a experiência do confinamento precisa ser administrada de modo a transformar o ambiente no qual as pessoas estão isoladas em um lugar que lhes agregue sentido além da proteção física e que possa proporcionar conforto, relaxamento e produtividade (JESUS, 2004). Logo, a prática da EA, associada à interdisciplinaridade, pode resgatar esses requisitos, na perspectiva de tornar esse período menos estressante e mais tranquilo do ponto de vista clínico (DA CONCEIÇÃO SILVA et al., 2020).

Segundo ZACARIAS e HIGUCHI (2017), o comportamento humano também reflete em muitos aspetos sobre a relação pessoa-ambiente. Nessa ótica, entende-se que, para que haja uma mudança de comportamento das pessoas em relação às questões ambientais, faz-se necessário o exercício constante da educação para fazer face ao atual cenário de pandemia, no qual os ambientes (externos e internos) precisaram ser ressignificados.

Para terminar, SILVA et al (2018), apresentaram a educação ambiental crítica (EAC) como alternativa para conscientização das pessoas, por via de construção coletiva de um projeto civilizatório mais justo, promovendo uma aliança com o planeta e lutando contra o 
conformismo trágico, dado as questões socioambientais. Faz-se necessária uma mudança, uma revolta, provocada pela educação ambiental, como forma de garantir a sobrevivência com qualidade ambiental da vida. É nesse sentido que se propõe acima a incorporação do termo “one education”, uma única educação, para ser aplicada a EAC, pois seria sinônimo de educação cidadã ou educação planetária, como denominam outros autores (MORIN, 1997).

Com base nos destaques teóricos e metodológicos da educação ambiental crítica e do conceito de promoção da saúde, apresenta-se a ideia de promover saúde única usando como vertente educacional, uma educação única, para proporcionar saúde planetária, através da estruturação da cidadania planetária. O papel da educação ambiental é essencial e transformador, disseminando a ideia do cuidado, do compartilhamento, do empoderamento do ser humano com o cuidar do planeta, negando o paradigma da dominação do mesmo (SILVA et al., 2018).

\section{CONCLUSÕES}

Das diversas fontes consultadas, de forma qualitativa, tornou-se possível trazer uma descrição parcial do atual cenário envolvente, o mundo com vivendo com o novo corona vírus

- COVID-ı9, daí, deduzir alguns resultados e levantar um conjunto de discussões inerentes o que conduziu as seguintes conclusões:

As caraterísticas do meio ambiente podem condicional os níveis baixos/alto de infecção pelo novo corona vírus, estudos demostram que as condições causadas pela intervenção humana sobre o meio ambiente, transformam-se, alterando suas caraterísticas naturais, o que condiciona o surgimento de doenças novas e ou propagação das já existentes. No caso vertente o meio físico e suas condições é determina para a disseminação do COVID19.

O "novo normal", condição imposta pelo COVID-ı, que envolve o confinamento e permanecia domiciliar por mais tempo, contribui taxativamente para o aumento no consumo de diversos produtos a nível mundial, pressionando mais a fonte de obtenção e consequente aumento nos níveis de geração de resíduos e sua gestão. 
As medidas cautelares adotadas em todo o mundo como forma de conter os níveis de propagação do COVID-ı, figuram-se de extrema importância temporária sobe ponto de ganho ambiental, visto que, houve notável redução nos níveis de poluição, principalmente urbana, onde as pessoas se aglomeram fluentemente. A conservação do meio ambiente, evidencia-se também pelos níveis de poluição atmosférica que foram largamente reduzidos com redução das emissões de gases de efeito de estufa. Aspecto detectado por inúmeros satélites climáticos pelo mundo.

A educação ambiental se torna imprescindível para munir os cidadãos e sociedades de modo a tornar mais resilientes e vigilantes ao cenário imposto pelo COVID-19 no mundo. A educação ambiental apresenta aos países a possibilidade de estar no mundo de forma diferente, promovendo o diferencial no modo de vida da sociedade através da vivência de determinados princípios como: formas de prevenção, as origens do vírus, como conter o vírus para que se possa voltar a quase normalidade.

\section{REFERÊNCIAS BIBLIOGRÁFICAS}

BORGES, André - ESTADAO (2020). Lixo hospitalar do coronavírus cresce pelo menos quatro vezes e vira "bomba relógio" da doença. Disponível em:

https://saude.estadao.com.br/noticias/geral,lixo-hospitalar Acesso em: 29/05/202I.

CONJO, Manuel Pastor Francisco et al. A importância do professor recuperador na escola para fazer face a retoma das aulas no período de covid-ı́ em Moçambique (caso de estudo município de Boane-bairro Campoane). Revista Ibero-Americana de Humanidades, Ciências e Educação, v. 7, n. 4, p. 855-868, 2021.

DA CONCEIÇÃO SILVA, Delmira Santos; DOS SANTOS, Marília Barbosa; SOARES, Maria José Nascimento. Impactos causados pela COVID-ı: um estudo preliminar. Revista Brasileira De Educação Ambiental (RevBEA), v. 15, n. 4, p. 128-147, 2020

DA COSTA, Isabella Fernanda Rangel Mendes. BREVES CONSIDERAÇÕES SOBRE SANEAMENTO, DESENVOLVIMENTO SUSTENTÁVEL E GESTÃO AMBIENTAL 
URBANA NO PERÍODO PÓS-PANDEMIA DE COVID-ig. /BRIEF CONSIDERATIONS ON SANITATION, SUSTAINABLE DEVELOPMENT AND URBAN ENVIRONMENTAL MANAGEMENT IN THE POST-PANDEMIC PERIOD OF COVID-19. P. I28. Revista Jurídica Eletrônica da UFPI, v. 7, n. oI, 2020.

https://comunicata.ufpi.br/index.php/raj/article/view/ıI720

DE SOUZA, Ligia da Paz. A pandemia da COVID-ıg e os reflexos na relação meio ambiente e sociedade. Revista Brasileira de Meio Ambiente, v. 8, n. 4, 2020.

DE TROI, Marcelo; QUINTILIO, Wagner. Coronavírus: lições anti - negacionistas e o futuro do planeta. SciELO em Perspectiva. v. 15, n. 05, p. 2020, Disponível em: https://blog. scielo. org/blog/2020/03/31/coronavirus-licoes-anti-negacionistas-eo-futuro-do-planeta/

DO CARMO, Ana Carolina Roma et al. COVID-ı9 e Meio Ambiente: Uma Relação Essencial em Frente ao Pânico de uma Pandemia. Revista Mosaico, v. II, n. 2, p. 19-34, 2020.

GRAULT, Carlos Eduardo et al. Políticas públicas para doenças transmitidas por vetores: situação atual e educação como alternativa. 2018.

HE, Hongwei; HARRIS, Lloyd. The impact of Covid-r9 pandemic on corporate social responsibility and marketing philosophy. Journal of Business Research, v. II6, p. I76-I82, 2020. JESUS, Octávio Manuel. Estrategia Didáctico - Metodológica Para El Tratamento de La Educación Ambiental En Los Programas de Geografía de Los Preuniversitarios de Mozambique. Ed. TRIcontinental, 2004.

JACOBI, P. Educação ambiental, cidadania e sustentabilidade. Cadernos de pesquisa, n. II8, p. 189-206, 2003.

LIM, Stephen S. et al. A comparative risk assessment of burden of disease and injury attributable to 67 risk factors and risk factor clusters in 21 regions, 1990-2010: a systematic analysis for the Global Burden of Disease Study 2010. The lancet, v. 38o, n. 9859, p. 2224-226o, 2012. 
LOH, E. H.; ZAMBRANA-TORRELIO, C.; OLIVAL, K. J. et al. Targeting Transmission Pathways for Emerging Zoonotic Disease Surveillance and Control. Vector Borne Zoonotic Dis.; vol. 15, n.ㅇ 7, 2015, pp. 432-7.

MARINELLI, Natália Pereira et al. Evolução de indicadores e capacidade de atendimento no início da epidemia de COVID-ı9 no Nordeste do Brasil, 2020. Epidemiologia e Serviços de Saúde, v. 29, p. e2020226, 2020.

MICOA. Diretiva Técnica para a implantação e operação de Aterros sanitários em Moçambique. MICOA, 2010

MIGUEL, José Pereira; REIS, Maria de Fátima. O Impacto do meio ambiente sobre as doenças. Anais da Academia Nacional de Medicina de Portugal, v. 5, p. I-20, 2015.

MORIN, E. Da ciência a consciência. Rio de Janeiro: Bertrand Basil, 1997.

MUNDIAL, Banco. Relatório sobre o Desenvolvimento Mundial 1993-investindo na saúde. 2019.

SANTOS, Marília Barbosa; SOARES, Maria José Nascimento. Impactos causados pela COVID-ı9: um estudo preliminar. Revista Brasileira De Educação Ambiental (Rev. BEA), v. I5, n. 4, p. 128-I47, 2020.

https://periodicos.unifesp.br/index.php/revbea/article/view/I0722

SCHMIDT, Rosana Andreatta Carvalho. A questão ambiental na promoção da saúde: uma oportunidade de ação multiprofissional sobre doenças emergentes. PHYSIS: Revista de Saúde Coletiva, v. 17, n. 2, p. 373-392, 2007.

SEVERINO, A.J. Metodologia do Trabalho Científico. São Paulo: Editora Cortez, 2007. I54p.

SILVA, Antônio Augusto Moura da. Sobre a possibilidade de interrupção da epidemia pelo coronavírus (COVID-ı) com base nas melhores evidências científicas disponíveis. 2020. 
https://www.scielosp.org/article/rbepid/2020.v23/e200021/

SILVA, Clélia Christina Mello et al. Mudanças climáticas, Saúde e Educação Ambiental como Política Pública em tempos de crise socioambiental. 2018.

https://www.arca.fiocruz.br/handle/icict/31434

UFJF (2020). Pandemia e Meio Ambiente: Impactos momentâneos ou nova normalidade? Disponível em: https://www2.ufjf.br/noticias/2020/04/24/pandemia-e-meio-ambienteimpactos-momentaneos-ou-nova normalidade/. Acesso em: 28/05/202I.

WORLD HEALTH ORGANIZATION et al. WHO Director-General's opening remarks at the media briefing on COVID-I9-II March 2020.

YOUNG, Carlos Eduardo Frickmann; MATHIAS, João Felippe Cury Marinho. Covid-ı,, meio ambiente e políticas públicas. 2020 .

ZACARIAS, E. F. J.; HIGUCHI, M. I. G. Relação pessoa-ambiente: caminhos para uma vida sustentável. Interações (Campo Grande), v. 18, n. 3, p. 121-129, 2017. 